OPEN ACCESS

Edited by:

Ruixin Zhu,

Tongji University, China

Reviewed by:

Mario M. D'Elios,

University of Florence, Italy

Gautham Yepuri,

University of Fribourg, Switzerland

*Correspondence:

Shih-Wei Lai

wei@mail.cmuh.org.tw

${ }^{\dagger}$ These authors have contributed equally to this work.

Specialty section:

This article was submitted to Gastrointestinal and Hepatic

Pharmacology,

a section of the journal

Frontiers in Pharmacology

Received: 29 May 2017 Accepted: 04 July 2017

Published: 19 July 2017

Citation:

Cheng K-C, Liao K-F, Lin C-L and Lai S-W (2017) Correlation of Proton

Pump Inhibitors with Pulmonary

Tuberculosis: A Case-Control Study in

Taiwan. Front. Pharmacol. 8:481.

doi: 10.3389/fphar.2017.00481

\section{Correlation of Proton Pump Inhibitors with Pulmonary Tuberculosis: A Case-Control Study in Taiwan}

\author{
Kao-Chi Cheng ${ }^{1,2+}$, Kuan-Fu Liao ${ }^{3,4,5 t}$, Cheng-Li Lin ${ }^{1,6}$ and Shih-Wei Lai ${ }^{1,2 *}$ \\ ${ }^{1}$ College of Medicine, China Medical University, Taichung, Taiwan, ${ }^{2}$ Department of Family Medicine, China Medical University \\ Hospital, Taichung, Taiwan, ${ }^{3}$ Department of Internal Medicine, Taichung Tzu Chi General Hospital, Taichung, Taiwan, \\ ${ }^{4}$ College of Medicine, Tzu Chi University, Hualien, Taiwan, ${ }^{5}$ Graduate Institute of Integrated Medicine, China Medical \\ University, Taichung, Taiwan, ${ }^{6}$ Management Office for Health Data, China Medical University Hospital, Taichung, Taiwan
}

Background and Objectives: Although the relationship between the use of proton pump inhibitors (PPIs) and pulmonary tuberculosis (TB) in Taiwan published in 2014. Due to just only one article and not enough comprehensively, we explore this issue.

Methods: We conducted a population-based case-control study to identify 9,422 subjects aged 20 years or older with newly diagnosed pulmonary TB in 2000-2013 as test cases. We then randomly selected 9,422 subjects aged 20 years or older without pulmonary TB as controls. Both cases and controls were matched in terms of sex, age, and comorbidities. Use of PPIs were defined as subjects who had had at least one prescription for these medications before the index date. No use was defined as subjects who had never had a prescription for PPIs before the index date. The odds ratio (OR) and 95\% confidence interval $(\mathrm{Cl})$ for pulmonary TB associated with PPI use was estimated using the logistic regression model.

Results: The OR of pulmonary TB was 1.31 for subjects who had used PPIs $(95 \% \mathrm{Cl}$ $1.22,1.41)$ compared with those with no use of the medications. Sub-analysis revealed the OR of pulmonary TB in subjects using PPI per increasing microgram was 1.25 (95\% Cl 1.19, 1.30).

Conclusions: PPI use is associated with a 1.3-fold increase in odds of developing pulmonary TB in Taiwan. There is a dose-related response between PPI use and pulmonary TB.

Keywords: pulmonary tuberculosis, proton pump inhibitors, Taiwan National Health Insurance Program

\section{INTRODUCTION}

Gastric acid plays a major role in decontaminating the upper gastrointestinal tract. A review article published about 30 years ago sought to determine the relationship between gastric secretion and ingested organisms resulting in possible infection (Howden and Hunt, 1987). Due to progress and recent advances in clinical pharmacology, acid-suppressive agents, including proton pump inhibitors (PPIs), have seen widespread use for treating peptic ulcers and acid reflux esophageal disease (Noguerado et al., 2002; Strid et al., 2003). Over the last 2-3 decades, PPIs were common used for acid suppressive agents in primary and specialty care with excellent safety (Sheen and Triadafilopoulos, 2011). A previous article revealed that PPIs appeared to be more effective than 
histamine 2 receptor antagonists (H2RAs) in preventing clinically important and overt upper gastrointestinal bleeding (Alhazzani et al., 2013).

Previous studies have described the relationship between PPI use and several enteric infections, such as Salmonella enteritis and Clostridium difficile colitis (Dial et al., 2005; Rodríguez et al., 2007), including spontaneous bacterial peritonitis in severe cirrhotic patients (Bajaj et al., 2009). Several research works have indicated that, besides the gastrointestinal system, PPIs are positively associated with infections of the respiratory system, such as community- or hospital-acquired pneumonia (Gulmez et al., 2007; Sarkar et al., 2008; Jager et al., 2012). However, few studies have indicated whether this association was related to low-dose or short-term PPI use (Giuliano et al., 2012; Filion et al., 2013). In addition to hospital- or community-acquired pneumonia, Mycobacterium tuberculosis (TB)-associated infection exerts significant burdens on the health-care systems of developing countries, including Taiwan (Hsueh et al., 2006).

Previous articles discussing the association between pulmonary $\mathrm{TB}$ and any degree of gastrectomy are scarce, and most of them do not include up-to-date technologies and true mechanism (Boman, 1956; Thorn et al., 1956). To date, the real role of gastric acid in pulmonary $\mathrm{TB}$ patients remains unknown. Although the relationship between the use of PPIs and pulmonary tuberculosis (TB) in Taiwan, similar to our study, published in 2014 (Hsu et al., 2014). Due to just only one article and not enough comprehensively (just focused on prescription period of PPIs only), we utilized the Taiwan National Health Insurance Program database to plan and conduct this study for exploring the associations completely and definitely.

\section{METHODS}

\section{Data Source}

Taiwan is an independent country with a population of over 23 million (Chao et al., 2015; Chen et al., 2015; Ho and Chang, 2015; Hsiao et al., 2015; Hung and Ku, 2015; Lin and Lin, 2016; Lin et al., 2016a; Maa and Leu, 2016; Ooi, 2016; Yu et al., 2016). We conducted a population-based case-control study using data from the Taiwan National Health Insurance Program. This insurance program was established in March 1995 and covers $99 \%$ of Taiwan's population (National Health Insurance Research Database, 2017). Details of this program can be found in previous studies (Lai et al., 2010, 2012; Hung et al., 2011; Cheng et al., 2012; Tsai et al., 2016). The present study was approved by the Research Ethics Committee of China Medical University (CMUH-104-REC2-115).

\section{Participants}

We identified subjects aged 20 years or older with newly diagnosed pulmonary TB (International Classification of Diseases, Ninth Revision, Clinical Modification, ICD-9 codes 010, 011, 012, and 018) from 2000 to 2013 as test cases. The date of pulmonary TB diagnosis was defined as the index date. Subjects who were not diagnosed with pulmonary TB were randomly selected from the same database as controls. Both cases and controls were matched in terms of sex, age (5-year intervals), and comorbidities.

\section{Comorbidities Potentially Related to Pulmonary PT}

Comorbidities that could potentially be related to pulmonary $\mathrm{TB}$, including alcohol-related diseases, asbestosis, chronic kidney disease, chronic obstructive pulmonary disease, diabetes mellitus, human immunodeficiency virus infection, gastrectomy, pneumoconiosis, splenectomy, and chronic liver diseases, such as cirrhosis, hepatitis B infection, hepatitis $\mathrm{C}$ infection, and other forms of chronic hepatitis, were assessed. All comorbidities were diagnosed with ICD-9 codes. The accuracy of these codes has been examined in previous studies (Lai et al., 2013a,b, 2014a,b, 2017; Hung et al., 2016; Lai, 2016; Lin et al., 2016a,b; Shen et al., 2016; Hsu et al., 2017; Liao et al., 2017a,b).

\section{Measurements of PPI and H2RA Use}

The PPIs available in Taiwan between 2000 and 2013 and considered in this study included esomeprazole, lansoprazole, omeprazole, pantoprazole, and rabeprazole. Patients' prescription histories of PPIs and H2RAs were included in this study. Use of medications was defined as prescription any of the medications studied in this work before the index date. No use of medication was defined as no history of prescription of any of the medications studied in this work before the index date.

\section{Statistical Analysis}

We compared the distributions of demographic status, PPI use, H2RA use, and comorbidities between cases and controls using the chi-squared test for categorized variables. The $t$ test was used to test differences in mean age and mean duration of exposure to PPIs between cases and controls. The univariable unconditional logistic regression model was used to measure odds ratios (ORs) and 95\% confidence intervals (CIs) and determine the association between pulmonary TB and PPI use. We also analyzed dose-related responses to PPI use. All analyzes were performed using SAS software (version 9.2; SAS Institute, Inc., Cary, NC, USA), and results were considered statistically significant when two-tailed $P$-values were $<0.05$.

\section{RESULTS}

\section{Characteristics of the Study Population}

As shown in Table 1, we identified 9,422 cases with newly diagnosed pulmonary TB between 2000 and 2013 and 9,422 controls without the disease. Both cases and controls showed similar distributions of sex and age. The mean ages (standard deviation) of patients with and without primary TB were 59.6 (17.1) years and 59.5 (17.1) years, respectively, and these values did not show statistical significance ( $t$-test, $P=0.8)$. The mean durations of PPI use (standard deviation) of cases and controls were 3.19 (5.96) and 3.49 (6.06) months, respectively; these values did not show statistical significance ( $t$-test, $P=0.13$ ). While cases with pulmonary TB were more likely to report PPI 
TABLE 1 | Information and comorbidities between pulmonary tuberculosis cases and controls.

\begin{tabular}{|c|c|c|c|c|c|}
\hline \multirow[t]{2}{*}{ Variable } & \multicolumn{2}{|c|}{ Non-tuberculosis $N=9422$} & \multicolumn{2}{|c|}{ Tuberculosis $N=9422$} & \multirow[t]{2}{*}{$P$-value* } \\
\hline & $n$ & $\%$ & $n$ & $\%$ & \\
\hline Sex & & & & & 0.88 \\
\hline Female & 3,000 & 31.8 & 3,010 & 31.9 & \\
\hline Male & 6,422 & 68.2 & 6,412 & 68.1 & \\
\hline Age group (years) & & & & & 0.99 \\
\hline 20-39 & 1,551 & 16.4 & 1,549 & 16.4 & \\
\hline $40-64$ & 3,474 & 36.9 & 3,472 & 36.9 & \\
\hline $65-84$ & 4,397 & 46.7 & 4,401 & 46.7 & \\
\hline Age (years), mean (standard deviation) ${ }^{\dagger}$ & 59.5 & $(17.1)$ & 59.6 & $(17.1)$ & 0.8 \\
\hline Duration of exposure to proton pump inhibitors (months), mean (standard deviation) ${ }^{\dagger}$ & 3.49 & $(6.06)$ & 3.19 & $(5.96)$ & 0.13 \\
\hline Ever use of proton pump inhibitors & 1,694 & 18 & 2,102 & 22.3 & $<0.001$ \\
\hline Ever use of histamine-2 receptor antagonists & 371 & 3.94 & 346 & 3.67 & 0.34 \\
\hline \multicolumn{6}{|l|}{ COMORBIDITIES } \\
\hline Alcohol-related disease & 717 & 7.61 & 745 & 7.91 & 0.45 \\
\hline Asbestosis & 1 & 0.01 & 1 & 0.01 & 0.99 \\
\hline Chronic liver disease & 1,637 & 17.4 & 1,674 & 17.8 & 0.48 \\
\hline Chronic obstructive pulmonary disease & 4,111 & 43.6 & 4,136 & 43.9 & 0.71 \\
\hline Chronic kidney disease & 459 & 4.87 & 468 & 4.97 & 0.76 \\
\hline Diabetes mellitus & 1,433 & 15.2 & 1,477 & 15.7 & 0.38 \\
\hline Human immunodeficiency virus infection & 21 & 0.22 & 21 & 0.22 & 0.99 \\
\hline Gastrectomy & 9 & 0.1 & 9 & 0.1 & 0.99 \\
\hline Pneumoconiosis & 87 & 0.92 & 75 & 0.80 & 0.34 \\
\hline Splenectomy & 2 & 0.02 & 2 & 0.02 & 0.99 \\
\hline
\end{tabular}

Data are presented as the number of subjects in each group with percentages given in parentheses, or mean with standard deviation given in parentheses.

${ }^{*}$ Chi-square test, and ${ }^{\dagger} t$-test comparing subjects with and without pulmonary tuberculosis.

use than controls (22.3 vs. $18 \%$, chi-square test, $P<0.001)$, no significant difference in H2RA use or other comorbidities was observed between cases and controls (Chi-square test, $P>0.05)$.

\section{Pulmonary Tuberculosis Associated with Proton Pump Inhibitor Use}

In Table 2, analyzes using the univariable unconditional logistic regression model showed that that the OR of pulmonary TB was 1.31 for subjects who had used PPIs (95\% CI 1.22, 1.41) compared with subjects who had never used PPIs. Because no other variable was significantly related to pulmonary $\mathrm{TB}$ during univariable analysis, we did not perform multivariable unconditional logistic regression analysis.

\section{Sub-analysis of the Association between Pulmonary Tuberculosis and Five Proton Pump Inhibitors}

Table 3 shows an analysis of the dose-related responses to PPI use; here, the group with no PPI use was considered the reference group. The OR of pulmonary TB in subjects using PPI per increasing microgram was 1.25 (95\% CI 1.19, 1.30). These results indicate a dose-related response between PPI use and pulmonary TB.

\section{DISCUSSION}

PPIs have been commonly prescribed to patients with upper gastrointestinal tract bleeding or acid reflux-associated diseases in the last two decades (Hsu et al., 2014). These medications feature an excellent safety profile, and their benefits outweigh their risks in most patients worldwide (Sheen and Triadafilopoulos, 2011). Patients began using PPIs for extended periods of time without considering appropriate indications for primary and specialty care. This problem has intensified in Taiwan, especially in the last two decades (Chen et al., 2003). Achlorhydric stomach is usually accompanied by a weak protective mechanism for ingested organisms, which could bring about gastrointestinal (Howden and Hunt, 1987; Williams and McColl, 2006) and respiratory infections, such as hospital- or community-acquired pneumonia.

Although previous published article in 2014 associated with Taiwan general PPIs user populations and pulmonary TB patients had similar study design and article structure compared with ours (Hsu et al., 2014). Their result revealed that the relationship between PPIs and pulmonary TB patients became gradually faded when the drug prescription period extended. But in our study, we found that cases with pulmonary TB were more likely to have used PPIs only than controls without the disease. General speaking, the relationship between 
TABLE 2 | Odds ratio and 95\% confidence interval of pulmonary tuberculosis associated with proton pump inhibitors use and comorbidities.

\begin{tabular}{|c|c|c|}
\hline \multirow[t]{2}{*}{ Variable } & \multicolumn{2}{|c|}{ Crude } \\
\hline & OR & $(95 \% \mathrm{Cl})$ \\
\hline Sex (male vs. female) & 1.00 & $(0.94,1.06)$ \\
\hline Age (per 1 year) & 1.00 & $(0.99,1.00)$ \\
\hline \multicolumn{3}{|c|}{ PROTON PUMP INHIBITORS (NEVER USE AS A REFERENCE) } \\
\hline Ever use & 1.31 & $(1.22,1.41)$ \\
\hline \multicolumn{3}{|c|}{ HISTAMINE-2 RECEPTOR ANTAGONISTS (NEVER USE AS A REFERENCE) } \\
\hline Ever use & 0.93 & $(0.80,1.08)$ \\
\hline \multicolumn{3}{|l|}{ COMORBIDITIES (YES VS. NO) } \\
\hline Alcohol-related disease & 1.04 & $(0.94,1.16)$ \\
\hline Asbestosis & 1.00 & $(0.06,16.0)$ \\
\hline Chronic liver disease & 1.03 & $(0.95,1.11)$ \\
\hline Chronic obstructive pulmonary disease & 1.01 & $(0.95,1.07)$ \\
\hline Chronic kidney disease & 1.02 & $(0.89,1.17)$ \\
\hline Diabetes mellitus & 1.04 & $(0.96,1.12)$ \\
\hline Human immunodeficiency virus infection & 1.00 & $(0.55,1.83)$ \\
\hline Gastrectomy & 1.00 & $(0.40,2.52)$ \\
\hline Pneumoconiosis & 0.86 & $(0.63,1.17)$ \\
\hline Splenectomy & 1.00 & $(0.14,7.10)$ \\
\hline
\end{tabular}

Cl: confidence interval.

TABLE 3 | Odds ratio and 95\% confidence interval of pulmonary tuberculosis in relation to cumulative dosage of proton pump inhibitors use by logistical regression model.

\begin{tabular}{lccc}
\hline Variable & $\begin{array}{c}\text { Case number/ } \\
\text { control number }\end{array}$ & Crude OR & (95\% Cl) \\
\hline $\begin{array}{l}\text { Never use of proton pump } \\
\text { inhibitors as a reference }\end{array}$ & $7320 / 7728$ & 1.00 & (reference) \\
$\begin{array}{l}\text { Proton pump inhibitors use } \\
\text { (increase in dosage per mg) }\end{array}$ & $2102 / 1694$ & 1.25 & $(1.19,1.30)$ \\
\hline
\end{tabular}

Cl: confidence interval.

PPIs (accumulative dose) and pulmonary $\mathrm{TB}$ is positive in our study, but negative in theirs (accumulative time). Because of the different results in prescription period or accumulative dosage between both of them, we planned and conducted our study for further investigation. This finding in our study may be explained by several hypotheses as follows.

First, long-term PPI use may weaken the protective mechanism of the stomach because PPIs inhibit gastric secretion. While the acidic environment of the stomach is generally free from bacteria (Vakil, 2009), bacterial colonies gradually develop and increase in achlorhydric or hypochlorhydric stomachs. Frequent and long-term use of PPIs is believed to promote infections in patients prescribed these medications.

Second, the possible explanation might be associated with lower immune status. M. tuberculosis shares risk factors similar to those of community-acquired pneumonia, such as diabetes mellitus, alcohol drinking, aging, and HIV infection (Hsu et al.,
2014), although our study showed no significant difference in these comorbidities between cases and controls. A recent largescale study in Japan and Taiwan revealed that gastrectomy could be associated with increased risk of pulmonary TB (Yokoyama et al., 2004; Huang et al., 2011), leading to poor immunity and nutritional states. We can confirm that the mechanism of gastrectomy is similar to that of PPI use and results in an achlorhydric or hypochlorhydric stomach. Therefore, the risk of developing pulmonary $\mathrm{TB}$ may increase because of limited stomach acid secretion and the poor immune status of a patient.

Finally, physicians in hospitals or local clinics may have difficulty in differentiating the symptoms of the initial stages of pulmonary TB and those of acid reflux-associated diseases, such as dry or chronic cough. The patients with chronic cough, disregarding whether pulmonary $\mathrm{TB}$ infections or not might be misdiagnosed or ignored, then PPI medication prescribed for treating acid reflux-associated chronic cough by physicians belong reasonable inference. Thus, some patients may still be infected with pulmonary TB even after PPI therapy. On the other words, PPI therapy should be withheld from patients with highly suspect pulmonary TB, even not prescribed PPI before confirm diagnosis of pulmonary TB.

In this study, we analyzed dose-related responses to PPI use and considered controls with no PPI use as the reference group. The dose-related response is understandable (Chou and Talalay, 1984). Patients prescribed high doses of the medications showed more extensive adverse effects than those prescribed relatively lower doses (Sheen and Triadafilopoulos, 2011). As PPI use is gradually increasing in Taiwan (Chen et al., 2003), physicians and specialists should pay more attention to the dose-related responses to and adverse effects of PPIs.

\section{LIMITATION}

One of the limitations of this work is underestimation of the numbers of patients with PPI use. Herein, we focused only on Taiwan's National Health Insurance Program database and ignored PPI or H2RA medications prescribed over the counter. Another limitation is diagnosis of pulmonary TB using ICD9 codes. Miscoding by physicians, an ambiguous definition of pulmonary $\mathrm{TB}$, and lack of sputum culture or chest X-ray could contribute to misdiagnosis of the disease. Finally, history, period, and dosage of PPI therapy were defined arbitrarily and without following any standard guideline. Rigorous evaluation of the definitions of pulmonary TB and manner of PPI use is recommended for future investigations.

\section{STRENGTH}

One of the strengths of the present study is that the set of ICD9 codes used has been validated in previous published studies (Lai et al., 2013a,b, 2014a,b, 2017; Hung et al., 2016; Lai, 2016; Lin et al., 2016a,b; Shen et al., 2016; Hsu et al., 2017; Liao et al., 2017a,b). The long observation period employed in our 
study (i.e., from 2000 to 2013) also endows our study with more credibility compared with other similar studies.

\section{CONCLUSION}

We conclude that PPI use is associated with a 1.3-fold increase in odds of developing pulmonary $\mathrm{TB}$ in Taiwan. There is a dose-related response between PPI use and pulmonary TB. Considering our results, evaluation of the risk of developing pulmonary TB may be necessary prior to prescribing the use of anti-suppressive agents.

\section{AUTHOR CONTRIBUTIONS}

KC and KL planned and conducted this study. They participated in the data interpretation, and also critically revised the article. CL conducted the data analysis and critically revised the article.

\section{REFERENCES}

Alhazzani, W., Alenezi, F., Jaeschke, R. Z., Moayyedi, P., and Cook, D. J. (2013). Proton pump inhibitors versus histamine 2 receptor antagonists for stress ulcer prophylaxis in critically ill patients: a systematic review and meta-analysis. Crit. Care Med. 41, 693-705. doi: 10.1097/CCM.0b013e3182758734

Bajaj, J. S., Zadvornova, Y., Heuman, D. M., Hafeezullah, M., Hoffmann, R. G., Sanyal, A. J., et al. (2009). Association of proton pump inhibitor therapy with spontaneous bacterial peritonitis in cirrhotic patients with ascites. Am. J. Gastroenterol. 104, 1130-1134. doi: 10.1038/ajg.2009.80

Boman, K. (1956). Tuberculosis occurring after gastrectomy. Acta Chir. Scand. 110, 451-457

Chao, P. C., Chuang, H. J., Tsao, L. Y., Chen, P. Y., Hsu, C. F., Lin, H. C., et al. (2015). The Malnutrition Universal Screening Tool (MUST) and a nutrition education program for high risk cancer patients: strategies to improve dietary intake in cancer patients. Biomedicine 5, 30-35. doi: 10.7603/s40681-015-0017-6

Chen, H. X., Lai, C. H., Hsu, H. Y., Huang, J. C., Wu, H. S., Ho, M. W., et al. (2015). The bacterial interactions in the nasopharynx of children receiving adenoidectomy. Biomedicine 5, 39-43. doi: 10.7603/s40681-015-0006-9

Chen, T.-J., Chou, L.-F., and Hwang, S.-J. (2003). Trends in prescribing proton pump inhibitors in Taiwan: 1997-2000. Int. J. Clin. Pharmacol. Ther. 41, 207-212. doi: 10.5414/CPP41207

Cheng, K. C., Chen, Y. L., Lai, S. W., Tsai, P. Y., and Sung, F. C. (2012). Risk of esophagus cancer in diabetes mellitus: a population-based case-control study in Taiwan. BMC Gastroenterol. 12:177. doi: 10.1186/1471-230X-12-177

Chou, T.-C., and Talalay, P. (1984). Quantitative analysis of dose-effect relationships: the combined effects of multiple drugs or enzyme inhibitors. $A d v$. Enzyme Regul. 22, 27-55. doi: 10.1016/0065-2571(84)90007-4

Dial, S., Delaney, J., Barkun, A. N., and Suissa, S. (2005). Use of gastric acidsuppressive agents and the risk of community-acquired Clostridium difficileassociated disease. JAMA 294, 2989-2995. doi: 10.1001/jama.294.23.2989

Filion, K. B., Chateau, D., Targownik, L. E., Gershon, A., Durand, M., Tamim, H., et al. (2013). Proton pump inhibitors and the risk of hospitalisation for community-acquired pneumonia: replicated cohort studies with meta-analysis. Gut 63, 552-558. doi: 10.1136/gutjnl-2013-304738

Giuliano, C., Wilhelm, S. M., and Kale-Pradhan, P. B. (2012). Are proton pump inhibitors associated with the development of community-acquired pneumonia? A meta-analysis. Expert Rev. Clin. Pharmacol. 5, 337-344. doi: $10.1586 /$ ecp. 12.20

Gulmez, S. E., Holm, A., Frederiksen, H., Jensen, T. G., and Hallas, J. (2007). Use of proton pump inhibitors and the risk of community-acquired pneumonia: a population-based case-control study. Arch. Intern. Med. 167, 950-955. doi: 10.1001/archinte.167.9.950
SL planned and conducted this study. He contributed to the conception of the article, initiated the draft of the article, and critically revised the article.

\section{ACKNOWLEDGMENTS}

This study was supported in part by Taiwan Ministry of Health and Welfare Clinical Trial Center (MOHW106-TDU-B-212133004), China Medical University Hospital, Academia Sinica Taiwan Biobank Stroke Biosignature Project (BM10501010037), National Research Program for Biopharmaceuticals (NRPB) Stroke Clinical Trial Consortium (MOST 105-2325-B-039-003), Tseng-Lien Lin Foundation in Taichung in Taiwan, Taiwan Brain Disease Foundation in Taipei in Taiwan, and Katsuzo and Kiyo Aoshima Memorial Funds in Japan. These funding agencies did not influence the study design, data collection and analysis, decision to publish, or preparation of the manuscript.
Ho, T. F., and Chang, C. C. (2015). A promising “TRAIL” of tanshinones for cancer therapy. Biomedicine 5, 29-35. doi: 10.7603/s40681-015-0023-8

Howden, C., and Hunt, R. (1987). Relationship between gastric secretion and infection. Gut 28, 96-107. doi: 10.1136/gut.28.1.96

Hsiao, I. H., Cho, D. Y., and Liu, C. L. (2015). Multifocal osteolytic lesions of the skull: a primary cavernous hemangioma mimicking a neoplastic invasive lesion. Biomedicine 5, 39-41. doi: 10.7603/s40681-015-0012-y

Hsu, F.-G., Sheu, M.-J., Lin, C.-L., Hsieh, Y.-W., and Lai, S.-W. (2017). Use of zolpidem and risk of acute pyelonephritis in women: a population-based casecontrol study in Taiwan. J. Clin. Pharmacol. 57, 376-381. doi: 10.1002/jcph.815

Hsu, W.-H., Kuo, C.-H., Wang, S. S., Lu, C.-Y., Liu, C.-J., Chuah, S.-K., et al. (2014). Acid suppressive agents and risk of Mycobacterium tuberculosis: case-control study. BMC Gastroenterol. 14:91. doi: 10.1186/1471-230X-14-91

Hsueh, P.-R., Liu, Y.-C., So, J., Liu, C.-Y., Yang, P.-C., and Luh, K.T. (2006). Mycobacterium tuberculosis in Taiwan. J. Infect. 52, 77-85. doi: 10.1016/j.jinf.2005.08.008

Huang, S.-F., Li, C.-P., Feng, J.-Y., Chao, Y., and Su, W.-J. (2011). Increased risk of tuberculosis after gastrectomy and chemotherapy in gastric cancer: a 7-year cohort study. Gastric Cancer 14, 257. doi: 10.1007/s10120-011-0037-1

Hung, C. C., and Ku, Y. W. (2015). Influencing and moderating factors analyzed in the group art therapy of two schizophrenic inpatients. Biomedicine 5, 36-38. doi: 10.7603/s40681-015-0024-7

Hung, S. C., Liao, K. F., Hung, H. C., Lin, C. L., Lai, S. W., and Lin, C. H. (2016). Nabumetone use and risk of acute pancreatitis in a case-control study. Pancreatology 16, 353-357. doi: 10.1016/j.pan.2016.03.003

Hung, S. C., Liao, K. F., Lai, S. W., Li, C. I., and Chen, W. C. (2011). Risk factors associated with symptomatic cholelithiasis in Taiwan: a populationbased study. BMC Gastroenterol. 11:111. doi: 10.1186/1471-230x-11-111

Jager, C. D., Wever, P. C., Gemen, E. F., Oijen, M., Gageldonk-Lafeber, A., Siersema, P., et al. (2012). Proton pump inhibitor therapy predisposes to community-acquired Streptococcus pneumoniae pneumonia. Aliment. Pharmacol. Ther. 36, 941-949. doi: 10.1111/apt.12069

Lai, S. W. (2016). Risks and benefits of zolpidem use in Taiwan: a narrative review. Biomedicine 6, 9-11. doi: 10.7603/s40681-016-0008-2

Lai, S. W., Chen, P. C., Liao, K. F., Muo, C. H., Lin, C. C., and Sung, F. C. (2012). Risk of hepatocellular carcinoma in diabetic patients and risk reduction associated with anti-diabetic therapy: a population-based cohort study. Am. J. Gastroenterol. 107, 46-52. doi: 10.1038/ajg.2011.384

Lai, S. W., Liao, K. F., Lai, H. C., Lin, C. L., and Sung, F. C. (2013a). Use of proton pump inhibitors correlates with increased risk of colorectal cancer in Taiwan. Asia Pac. J. Clin. Oncol. 9, 192-193. doi: 10.1111/ajco.12054

Lai, S. W., Liao, K. F., Lai, H. C., Lin, C. L., and Sung, F. C. (2013b). Proton pump inhibitors and risk of hepatocellular carcinoma: a case-control study in Taiwan. Acta Gastroenterol. Belg. 76, 348-350. doi: 10.1111/ajco.12054 
Lai, S. W., Liao, K. F., Liao, C. C., Muo, C. H., Liu, C. S., and Sung, F. C. (2010). Polypharmacy correlates with increased risk for hip fracture in the elderly: a population-based study. Medicine 89, 295-299. doi: 10.1097/MD.0b013e3181f15efc

Lai, S. W., Lin, C. L., and Liao, K. F. (2017). Risk of contracting pneumonia among patients with predialysis chronic kidney disease: a population-based cohort study in Taiwan. Biomedicine 7, 41-46.

Lai, S. W., Lin, C. L., Liao, K. F., and Tsai, S. M. (2014a). Increased risk of pulmonary tuberculosis among patients with appendectomy in Taiwan. Eur. J. Clin. Microbiol. Infect. Dis. 33, 1573-1577. doi: 10.1007/s10096-014-2112-0

Lai, S. W., Wang, I. K., Lin, C. L., Chen, H. J., and Liao, K. F. (2014b). Splenectomy correlates with increased risk of pulmonary tuberculosis: a case-control study in Taiwan. Clin. Microbiol. Infect. 20, 764-767. doi: 10.1111/1469-0691.12516

Liao, K. F., Cheng, K. C., Lin, C. L., and Lai, S. W. (2017a). Etodolac and the risk of acute pancreatitis. Biomedicine 7, 25-29. doi: 10.1051/bmdcn/2017070104

Liao, K. F., Huang, P. T., Lin, C. C., Lin, C. L., and Lai, S. W. (2017b). Fluvastatin use and risk of acute pancreatitis: a population-based case-control study in Taiwan. Biomedicine 7, 23-27.

Lin, H. F., Lai, S. W., Lin, W. Y., Liu, C. S., Lin, C. C., and Chang, C. M. (2016a). Prevalence and factors of elevated alanine aminotransferase in central Taiwan a retrospective study. Biomedicine 6, 25-30. doi: 10.7603/s40681-016-0011-7

Lin, H. F., Liao, K. F., Chang, C. M., Lai, S. W., Tsai, P. Y., and Sung, F. C. (2016b). Anti-diabetic medication reduces risk of pulmonary tuberculosis in diabetic patients: a population-based cohort study. Int. Med. J. 23, 458-463.

Lin, W. C., and Lin, C. H. (2016). Multidetector computed tomography in the evaluation of pediatric acute abdominal pain in the emergency department. Biomedicine 6, 20-24. doi: 10.7603/s40681-016-0010-8

Maa, M. C., and Leu, T. H. (2016). Src is required for migration, phagocytosis, and interferon beta production in Toll-like receptor-engaged macrophages. Biomedicine 6, 5-9. doi: 10.7603/s40681-016-0014-4

National Health Insurance Research Database (2017). National Health Insurance Research Database. Taiwan. Available online at: http://nhird.nhri.org.tw/en/ index.html (cited in March 1, 2017, English version).

Noguerado, A. A., Rodríguez, B. R., Zelaya, C. P., Sánchez, S. A., Antuña, B. F., Lutz, G. E., et al. (2002). Use of acid-suppressive medications in hospitalized patients. Anal. Med. Interna 19, 557-560.

Ooi, H. (2016). Bedside pleuroscopy in Taiwan: a great vision for critically-ill patients and intensivists. Biomedicine 6, 1-4. doi: 10.7603/s40681-016-0013-5

Rodríguez, L. A. G., Ruigómez, A., and Panés, J. (2007). Use of acid-suppressing drugs and the risk of bacterial gastroenteritis. Clin. Gastroenterol. Hepatol. 5, 1418-1423. doi: 10.1016/j.cgh.2007.09.010
Sarkar, M., Hennessy, S., and Yang, Y.-X. (2008). Proton-pump inhibitor use and the risk for community-acquired pneumonia. Ann. Intern. Med. 149, 391-398. doi: 10.7326/0003-4819-149-6-200809160-00005

Sheen, E., and Triadafilopoulos, G. (2011). Adverse effects of longterm proton pump inhibitor therapy. Digest. Dis. Sci. 56, 931-950 doi: 10.1007/s10620-010-1560-3

Shen, M. L., Liao, K. F., Tsai, S. M., Lin, C. L., and Lai, S. W. (2016). Herpes zoster correlates with pyogenic liver abscesses in Taiwan. Biomedicine 6, 24-29. doi: 10.7603/s40681-016-0022-4

Strid, H., Simrén, M., and Björnsson, E. S. (2003). Overuse of acid suppressant drugs in patients with chronic renal failure. Nephrol. Dial. Transplant. 18, 570-575. doi: 10.1093/ndt/18.3.570

Thorn, P., Brookes, V., and Waterhouse, J. (1956). Peptic ulcer, partial gastrectomy, and pulmonary tuberculosis. Br. Med. J. 1:603. doi: 10.1136/bmj.1.4967.603

Tsai, T. Y., Lin, C. C., Peng, C. Y., Huang, W. H., Su, W. P., Lai, S. W., et al. (2016). The association between biliary tract inflammation and risk of digestive system cancers: a population-based cohort study. Medicine 95:e4427. doi: 10.1097/MD.0000000000004427

Vakil, N. (2009). Acid inhibition and infections outside the gastrointestinal tract. Am. J. Gastroenterol. 104, S17-S20. doi: 10.1038/ajg.2009.47

Williams, C., and McColl, K. (2006). Review article: proton pump inhibitors and bacterial overgrowth. Aliment. Pharmacol. Ther. 23, 3-10. doi: 10.1111/j.1365-2036.2006.02707.x

Yokoyama, T., Sato, R., Rikimaru, T., Hirai, R., and Aizawa, H. (2004). Tuberculosis associated with gastrectomy. J. Infect. Chemother. 10, 299-302. doi: 10.1007/s10156-004-0334-2

Yu, C. C., Chien, C. T., and Chang, T. C. (2016). M2 macrophage polarization modulates epithelial-mesenchymal transition in cisplatininduced tubulointerstitial fibrosis. Biomedicine 6, 29-34. doi: 10.7603/s40681016-0005-5

Conflict of Interest Statement: The authors declare that the research was conducted in the absence of any commercial or financial relationships that could be construed as a potential conflict of interest.

Copyright (C) 2017 Cheng, Liao, Lin and Lai. This is an open-access article distributed under the terms of the Creative Commons Attribution License (CC BY). The use, distribution or reproduction in other forums is permitted, provided the original author(s) or licensor are credited and that the original publication in this journal is cited, in accordance with accepted academic practice. No use, distribution or reproduction is permitted which does not comply with these terms. 